\title{
O EPISÓDIO DA SERRA DO RODEADOR (1817-20): UM MOVIMENTO MILENAR E SEBASTIANISTA
}

\author{
René Ribeiro \\ Professor da Faculdade de Filosofia de Pernambuco \\ da Universidade do Recife
}

Dentre os vários movimentos messiânicos surgidos no Brasil nenhum parece tão mal estudado quanto o que teve lugar na Serra do Rodeador, município de Bonito (Pernambuco), pouco depois da revolução de 1817 e violentamente reprimido pelo governador Luiz do Rego Barreto. Duas referências a êsse movimento encontram-se na literatura: um breve relato de Pereira da Costa, em seu Folk-lore Pernambucano, cujo tom demonstra que o autor teve conhecimento e endossou os têrmos da carta daquele governador de Pernambuco em que relatava as providências que tomara e procurava justificar-se perante o ministro Villa-Nova Portugal 1 ; um artigo de J. Augusto da Costa publicado na Revista Brasileira ${ }^{2}$, em que se percebe ter o autor familiaridade com tôda a documentação sôbre o caso, recolhida ao Arquivo Nacional, porém que infelizmente foi deixado incompleto.

O conjunto de documentos sob o título de "Devassa acêrca dos acontecimentos da Serra do Rodeador" encontra-se coligido nos volumes catalogados como Governadores de Pernambuco. Correspondência com o Ministério do Reino 1820-21 da Seç̧ão de Documentos do Arquivo Nacional ${ }^{3}$. Inclui relatórios, planos de marcha e dispositivos de ataque do chefe da expedição militar, efetivos e listas das baixas dos corpos de tropa, informações e depoimentos dos espias utilizados, carta circunstanciada do governador Luiz do Rego Barreto e os depoimentos de homens e mulheres tomados prisioneiros. Êsses documentos (que tivemos oportunidade de compulsar ùltimamente, por indicação do historiador José Antonio Gonsalves de Melo) estão em muito bom estado e surpreendem pela clareza e meticulosidade com que foram redigidos, permitindo a utilização de informações preciosas para o historiador e de igual modo para o sociólogo cu o psicólogo social mais exigentes na consulta a fontes primárias sôbre acontecimentos tão difíceis de fixar como os movimentos milenares e messiânicos.

Dêsse documentário se deduz que sob a liderança de um ex-soldado do 12. Batalhão de Milícias, de nome Silvestre José dos Santos, reuniam-se mais de duzentos homens ("e que de mulheres maior numero") 4, "arma- 
dos de bacamartes, faccas, e parnahibas, e polvora bastante para se defenderem" 5, num local "a legua e meia distante do povoado do Bonito e trinta e seis desta Praça" 6 (Recife). Ali assistiam às prédicas e revelações de Silvestre, sabendo-se ainda "que esta reunião era sempre de noite que primeiramente rezão o terço e o officio de Nossa Senhora e depois acabada a reza passavão revista as armas a ver o estado de cada huma" cu exercitavam-se no seu manejo e realizavam marchas ao som de uma rabeca. Quanto às mulheres, terminadas as orações, "faziam penitencia" 7, à semelhança dos grupos de flagelantes que ainda hoje se encontram no sertão nordestino.

Silvestre José dos Santos tentara anteriormente reunir um grupo de seguidores em Lages do Canhoto, Alagoas, mas fôra impedido pelas autoridades locais "por causa das profecias que fazia e de certas doutrinas religiosas que misturava-lhes". Estabeleceu-se então no município pernambucano de Bonito em terras do sargento de ordenanças João Francisco -- "o qual foi tão bem da sociedade, e offereceo os seus bens, e deo-lhes alguns donativos" 8. O alto da Serra do Rodeador, perto de uma lapa, foi o sítio escolhido para suas pregações feitas a princípio em pequena cabana c posteriormente numa construção maior, ou "Mocambo que servia de capella". Ai tinha êle instaladas em altar uma imagem do Bom Jesus, outra de Nossa Senhora da Conceição e "muitos santos que o adorão entre estes hum de oiro que terá hum covado de altura". Assinalando a laje cravara uma cruz e fizera crer a seus seguidores "que sahirá de dentro cla pedra do lugar onde está huma Cruz a El Rey D. Sebastião com o seu Exercito, na qual pedra e lugar se ouvem fazer manejos d'armas, jogos d'espada, e instrumentos de musica tocando". Por isso o local passou a ser conhecido como o "lugar do milagre", ou do "encanto", ou "Cidade do Paraíso Terreal". Silvestre e seu principal auxiliar, Manoel Gomes das Virgens, também ex-soldado do 12.0 Batalhão de Milícias, intitulavam-se cie "procuradores de Jesus Cristo" e dirigiam tôdas as atividades do grupo à base de "revelações" que diziam receber da "Santa Milagrosa", pois "que erão os dois unicos que falavão com a Santa, e a quem ella dava as ordens do que elles devião fazer"9. Silvestre "pregava as revelações que elle expunha" e "sendo muito pobre e não sabendo lêr nem escrever fizesse [fazia] admirar a todos pelo que dizia, e fazia" 1". E' para salientar que à diferença de outros movimentos milenares, no caso atual o líder não se apresentava como o Messias, mas como profeta anunciador de uma nova era a ser inaugurada com o reaparecimento do Rei D. Sebastião e portavoz da Virgem que os guiaria no empreendimento militar-religioso.

À época da repressão, o grupo, a julgar do depoimento de Antonio Fereira, cunhado de Silvestre, devia contar com mais de duzentos homens, enquanto para Estevão Fernandes (outro membro do grupo aprisionado) seriam cento e cinqüenta. O governador Luiz do Rego Barreto, talvez 
pira diminuir o efeito provocado pelo massacre que ordenara, fixava-os nuns "sessenta homens, e muitas mulheres" 11, mas o tenente-coronel José de Sá Carneiro Pereira, comandante do ataque, refere ter incendiado a capela de palha "que queimou todos os feridos que estavão dentro chegando a mais de setenta inclusos algumas mulheres 12 .

As informações coligidas nos documentos indicam que a maioria dos participantes "era gente do povo" e os principais líderes, Silvestre José (ios Santos, Manoel Gomes das Virgens (os dois chefes), Antonio Gomes (sapateiro que dirigia os exercícios militares ou "Santa Marcha"), Goncalo Correia (que comandava as "revistas d'armas"), José Fernandes (um coos ajudantes nos ritos de iniciação dos novos sectários), Manoel da Paixão (cuja filha dava a penitência aos iniciandos), Estevão Fernandes (pai de José Fernandes), Valentim Alves, Manoel José, José Taboca, Severino (filho de Manoel José) e Antonio Pereira, cunhado de Silvestre. Dentre outras, Francisca Maria de Santa Anna, Feliciana Maria da Conceição e Joana Batista eram as "procuradoras da honestidade das mulheres".

U grupo de sectarios de Siivestre recebeu organização nitidamente miLitar com quatro Capitães, quatro Alferes ("e hum destes Inspector") "os quais incustriavão a gente no exercicio" ou "manejo d'armas e manobras". U comandante e instrutor do $12 .^{\circ}$ Batalhão de Milicias, em carta ao governador Luiz do Kego Barreto, informava que o grupo de Silvestre "Vivendo em continuados exercicios, e rezas, tinhão a gente dos paizes circunvizinhos aterrada das forças, e encantada da santidade". Além disso, "Reconhecendo hum Rey imaginario, e autoridades estravagantes, com uniforme, e divizas militares a seu modo, tinhão fugido do gremio da sociedade e da observancia das leys; e, inventando milagres, e practicando horrendas sukerstições, havião aberrado dos principios da verdađeira Religião" 13. Daí afirmar o governador de Pernambuco "que ali se estava propagando hum scisma religioso, e politico ao progresso do qual era preciso quanto antes por ostaculos, porque o povo se hia allucinando" 14 .

Antonio Pereira, "trabalhador de enxada" e cunhado do chefe, diz em seu depoimento do processo de aliciamento e dos incentivos que encontrou para sua participação no grupo: "que haverá perto de trez annos que seu Cunhado Silvestre José dos Santos o procurava dizendo-lhe que tinha hum grande negocio a tratar com elle, e perguntando-lhe elle o que era, o dito seu Cunhado lhe perguntou se elle tinha animo de se ver entre chuva cie polvora e balla, a que elle respondeu que sim, e que então o dito seu Cunhado lhe propozera tantos bens, e tantas fortunas, que elle ficou desejoso de conseguir, pois que se dispunha a conquistar a Caza Santa de Jerusalem, e o Paraizo Terreal e a destruir todos aquelles que se oppozessem a tão sagrado fim pugnando pela Ley de Deus para que se devião reunir bem armados, e que elle a vista de tantas venturas acceitou, e então o dito seu Cunhado lhe mandou ensinar por outro hum grande nu- 
mero de orações [que elle acceitou, e que por serem cheias de supersti§ões não nas transcreveremos - regista o escrivão] e depois continuou a trabalhar com elle a bem do santo fim a que se tinham proposto" 15. José Fernandes, ferreiro, armeiro e coronheiro do grupo, esclarece em seu depoimento o caráter da verdadeira cruzada a que se propunham Silvestre ¿ seus seguidores. Diz êle que "havia para quatro mezes, que Silvestre José dos Santos, soldado do Batalhão de Milicias n. 12 o tinha convidado para viver na Serra do Rodeador aonde junto com outros defendessem a causa da verdadeira Fé, e Religião de Nosso Senhor Jesus Cristo, e de El Fiey D. Sebastião, e que devião estar bem armados para poderem combater quem se oppozesse contra este fim, e que depois quando tivessem maior numero devião sahir tomar Pernambuco e dirigirem-se resgatar os lugares Santos de Jeruzalem"16. O tenente Antonio Ribeiro Freire, que a mandado do seu comandante se fizera passar como adepto de Silvestre, para melhor informar as autoridades, acentua "que de noite fazião os seus ajuntamentos, rezavão as suas Orações, e depois faziam as suas marchas, e exercicios, tinham Ferreiro, ou Espingardeiro, que compunha as armas, e dizião, que aquela sociedade era mandada estar alli por Deos, pois que El Rey Dom Sebastião havia alli apparecer, e he, que era o verdadeiro Rey e toda aquella sociedade estava pronta para o deffender, que todos os que alli estavão serião muito felizes, e que elles se compadecião da infelicidade, dos que não estavão naquella sociedade, por que erão infelizes por força" 17. Matias Ramos da Costa, também enviado em missão de espionagem, igualmente regista as crenças sebastianistas e o caráter leniente da Cruzada: "que naquella sociedade estavão prontos para deffender ao seu Rey D. Sebastião José; que não obedecião a outro Rey senão a este, e a Deus, que El Rey D. Sebastião não tardava, que não aparecesse, e que estava d'alli a vinte cinco legoas, e que vinha rompendo agoas verdes com u punho do seu braço, e que outras muitas Coizas, que depois havião acontecer, que delles não tinhão pena por serem immortaes, e que só tinhão pena do povo, que ainda não tinha seguido a sua Ley, que elles hum dia havião sahir daquelle sitio" etc. ${ }^{18}$. Como solução de compromisso, antes de saírem'a campo "resgatar os lugares Santos de Jerusalem" e conquistar c. "Paraiso Terreal", admitiam que "querendo El Rey Dom João 6.o seguir a El Rey Dom Sebastião ainda El Rey Dom João $6 .^{\circ}$ havia ser bem premiado por Dom Sebastião" 19.

Essas idéias ingênuas e os mitos sebastianistas haviam tido largo curso $\epsilon \mathrm{m}$ Portugal durante longos anos e não estavam mesmo no princípio do século XIX de todo esquecidos. Com raiz na tradição judaico-cristã do millenium, veiculada no livro das Revelações e no Apocalipse com a previsão do estabelecimento do Quinto Império do Mundo, após a vinda do Messias, e o reaparecimento das tribos de Israel perdidas, as idéias messiânicas e milenaristas difundiram-se na Europa cristã e motivaram inú- 
meros movimentos populares à época das cruzadas, quando não algumas destas 20. Encontraram principalmente em Portugal com o episódio da morte e desaparecimento do rei $D$. Sebastião em sua desastrada campanha da África e as várias vicissitudes históricas dêsse país a mais ampla ressonância, ao ponto de dizer-nos J. Lucio de Azevedo ainda haver depois de 1820 "quem se ocupe de derrotar o Sebastianismo, fazendo aparecer o Egregio Encoberto na pessoa de D. João VI, ao regressar do Brasil" 21. Das Trovas do Bandarra (1530) à identificação de D. Sebastião com o mito do Encoberto e a subseqüente e atribulada carreira política do sebastianismo até seu relativo descrédito em 1813 (quando apareceu em Lisboa "certo criginal, vestido de Mouro, que se dizia enviado de D. Sebastião" 22 e que foi apenas objeto de galhofa) a difusão dos mitos sebastiânicos iria passar ao Brasil e aqui motivar movimentos como o do Rodeador (1817-20), o de Pedra Bonita (1838) e o de Canudos (1893-97). Idéias messiânicas e milenáristas estão na raiz dêstes e de outros movimentos mais recentes, como o do Contestado ou o do Padre Cícero do Joazeiro, atestando a vitalidade das crenças na idade de ouro sôbre a terra e no reino divino universal ${ }^{23}$.

As condições sociais em Pernambuco, à época do episódio da Serra do Rodeador, pareciam ser de grande instabilidade e insegurança pessoal. Acabara de ser subjugado o movimento republicano de 1817 e instalara-se lim govêrno repressivo e rudemente militarista sob Luiz do Rego Barreto. $\hat{I}$ ste mesmo, a depreender do primeiro parágrafo da sua carta ao Ministro cio Reino Thomas Antonio de Villa-Nova Portugal, parecia muito preocr pado com a repressão ao banditismo e aos clubes republicanos ("Depois que eu soube do bando de José de Barros, e do Clube do Boique" etc.). J. Augusto da Costa, no seu artigo incompleto sôbre o mesmo episódio de que nos ocupamos, diz um tanto apologèticamente: "Apezar do militarismo que existia, devastavam a capitania nessa epoca, como anteriormente, bandos de salteadores, quilombos de negros que atacavam as estradas e os povoados. A segurança individual e de propriedade fora da capital era quasi nenhuma. O celebre facinora José de Barros levava o terror por todo o interior da capitania, a quadrilha do padre Bandeira, que constava de uns trezentos homens, trazia o sertão em desassocego; a Cova da Onça, $\epsilon \mathrm{m}$ Iguarassu, e os indios bravios, em Cimbres, não deixavam o CapitãoGeneral um momento de tranquilidade, quando sobreveio o negocio do Rodeador" 24. Ele mesmo retira do depoimento de Antonio Ferreira razões mais particulares de insatisfação pessoal: "a vida era muito cara, que quem não tinha dinheiro não se podia enterrar nas igrejas e que as milicias deviam acabar" 25 .

Vida cara, impossibilidade econômica de entêrro condigno e terror ante os métodos do recrutamento militar àquela época, deviam facilitar o sucesso das pregações e promessas de Silvestre José dos Santos, além naturalmente da atração do maravilhoso e da ressonância de suas idéias mi- 
lenaristas e sebastianistas. Estevão Fernandes, por exemplo, dizia "que fôra convidado para hum encanto, e que este encanto consistia em apparєcer El Rey Dom Sebastião José" 26. Outro depoente "disse que hia ver ¿: Santidades que ali havião" 27. Ou então, faziam crer os dois chefes serem instrumentos da vontade divina que, se executada, traria a todos grandes vantagens: "que eram os dois unicos [Silvestre e Manoel Gomes] que fallavão com a Santa e a quem ella dava as ordens do que elles devião fazer, prometendo-lhe que elles dois serião principes, os pobres serião ricos, e os ricos augmentados" 28 . Também "se promettia huma felicidade imensa a quem alli entrasse" 29. O grupo passara a acolher desertores do 12..$^{\circ}$ Batalhão de Milícias, do qual ambos os chefes fizeram parte, e isso foi o que despertou inquietação entre as autoridades militares e deu-lhes uma medida da fôrça e disposição do grupo quando uma patrulha se viu cm dificuldades ao tentar capturar um soldado foragido que contara com a proteção dos do Rodeador. Luiz do Rego Barreto escreve sua página de sociologia da época na longa carta em que relata o episódio: "que uns sessenta homens, e muitas mulheres se havião entranhado na Serra do Rodeador, aonde vivião dados a superstições ridiculas, as quais derramavão, alliciando assim muitos credulos, cujo numero hia progredindo em virtude de uma notavel fascinação"... "Elles prometião sahir dentro em breve a pregar a sua [Religião] com arcabuz na mão. Quem sabe quanto estas maximas infernaes fascinão, apoyadas pela força, e sobre tudo por uma aparente austeridade (duas columnas, e sustentaculos de quantas herezias tem transtornado as sociedades) não deixará de dar a devida approvação ás medidas tomadas para prender estes novos apostolos do fanatismo, e da desobediencia a El Rey" 30 .

Intensa religiosidade, estruturação militar e grande austeridade eram características salientes dêsse grupo de obscuros cruzados do interior de Pernambuco.

As orações que abriam a rotina 'diária do ajuntamento eram chamadas "santos louvores" ou "as santas insinuações", ou a "santa devoção"; o sítio, "santa pedra" ou "logares santos"; o Rodeador tornou-se conhecido "como "Cidade do Paraiso Terreal". Um pombeiro, informante das autoridades militares, "diz que chegando ao Distrito do Bonito observou ,não se falar em outra couza mais que em tais homens, e seus milagres" e mais, "que os ditos homens são muito devotos por que exigem dos que querem alistar sc. confessem". Como surgissem dificuldades com os vigários e os capelães aiertados sôbre a existência dessas atividades religiosas não sancionadas pela Igreja, contornaram os fiéis o problema: "porem elles vão ao lugar ondi os ditos homens estão e se confessão a Nossa Senhora da Conceição e huma filha do principal cabeça, chamado Paixão he quem lança a absolvição, e lhe dá penitencia que logo cumpre pondo-se de joelhos até final" 31 . José Fernandes, participante ativo do grupo "respondeo que antes de en- 
trar erão confessados, e que na entrada erão conduzidos entre dous levando cada hum espada desembainhada, e que elle era hum destes; e que os conduzião até o Altar aonde juravão solenemente guardar segredo, e morrer na cauza da deffença de Nosso Senhor Jesus Cristo, e de El Rey D. Scbastião" 32. O tenente Antonio Ribeiro Freire foi levado "ao Sitio da reza que era uma Caza de palha, aonde tinhão varias Imagens", quando de sua pretensa adesão e "o mandarão confessar a huma Imagem, e lhe derão sua penitencia e vio elle testemunha huma ocasião o Silvestre e o Manoel Gomes hirem fazer Oração postos de joelhos, armados de espadas, pistollas e facas, e o José Fernandes, e o filho do Paixão cada hum tão bem armados e com as espadas desembainhadas, hum virado para a porta, outro virado para o Altar, e dizia a José Fernandes humas palavras, se havia alli quem se oppuzesse aquella Ley, e que fosse falso, ao que alli se determinava, e contra o que a Senhora determinava, e depois levantavão-se os que estavão de joelhos com as espadas na mão e fazião com que elle testemunha desse duas patacas de entrada; igualmente vio, que depois de rezarem principiavão á passar revista ás armas" etc. e "fazia-se marchas, e exercicios como tropa" 33. O alferes Joaquim José de Vasconcellos refere "que naquella noite, e em outras tres mais, que assistira a Santa Devoção como elles lhe chamavão e pondo-se todos nestas Oraçoens depunham as armas, que trazião, a excepção das curtas, que essas as conservavão á cinta, e depois disto pegavão nas armas, e punhão-se a fazer as suas marchas e revistas de armas até pela manhã" 34 .

A estrutura do grupo comportava os dois chefes ou "Procuradores de Jesus Christo", os quatro Capitães e os quatro Alferes, além de Procuradores e Procuradoras da honestidade dos homens e das mulheres, todos a distinguirem suas funções com divisas e rosetas multicores. Além disso, os "irmãos" (como eram conhecidos e se tratavam os fiéis) classificavam-se $€ \mathrm{~m}$ "sabidos", em número de 12, e "ensinados", que deveriam atingir a mil antes que se pusessem em marcha os cruzados. A revista às armas cabia a Gonçalo Correia, enquanto Antonio Gomes dirigia as "sanctas marchas". As mulheres mantinham-se alheias aos detalhes esotéricos do cerimonial porque "o segredo não era para ellas".

Uma das "procuradoras da honestidade das mulheres", Feliciana Maria da Conceição, esclareceu no processo o rigor das suas funções: "compor ats mulheres para estarem bem honestas nos seus vestuarios e não estarem juntas com os homens, visto que devia haver essas cautelas, sendo esses ajuntamentos á noite e vigiar que ellas estivessem acordadas e attentas".

Estavam crentes êsses novos cruzados no auxílio sobrenatural para o sucesso absoluto de sua emprêsa. Não sòmente surgiria El Rey Dom Sebastião "com o seu exercito" no momento oportuno, como "que quem alli estivesse, podia estar seguro, e livre de tudo" 35 , e que "aquella sociedade havia sahir hum dia daquelle Sitio, que se chamava Paraizo Terreal, e Nossa Senhora he que havia determinar e guiar" 36. Seguros da imorta- 
lidade e dispostos a "conquistar o mundo inteiro, quando fosse occasião, e isto pela Lei de Deos Verdadeiro" 37, no caso de serem hostilizados, "toda a sociedade havia desaparecer aos olhos da tropa" 38 . Também prometeram-lhe os seus líderes, "em nome da Santa Milagrosa que quando de alguma parte viesse tropa a ataca-los não tivessem susto pois que da sua parte havião de ter sempre dobrada força daquella que viesse ataca-los" 39, ou então, "que quando forem atacados o dito seu Rey D. Sebastião mandará huma embaixada ao Commandante della, e que lastimão a sorte dos que lá forem por que elles são imortais, e que então sahirão a campo castigar os que não quizerem alistar no seu partido, sabem que a tropa que os for atacar logo que os veja, e os seus prodigios depõem as armas, є se pação para ellas" 40 .

Vigiados de perto pelo capitão Manoel Bezerra, comandante do distrito, que fingia protegê-los e espionados por um seu filho, o alferes Antonio Bezerra, e pelo tenente do $12 .^{\circ}$ Batalhão de Milícias, Antonio Rikeiro Freire, "que sabem perfeitamente que amanhã he a noite em que todos os rebeldes se ajuntão no lugar do milagre, e que ha conferencia", nessa mesma noite de 25 de outubro de 1820 foi o sítio cercado pelas tropas para isso destacadas pelo governador. Parece terem se apercebido os do Rodeador da presença de tropas, mas é duvidosa a afirmativa de Luiz co Rego Barreto sôbre "a pertinacia da defeza; a constancia de seis horas de perfiado combate; a mortandade de huma e outra parte" que êle diz terem sido "espantosas", porquanto, "ao sentirem as tropas romperão em palmas, e vivas" 41. Percebe-se da parte de quem presidiu ao "Processo sumario e inquirição de testemunhas sobre o ajuntamento e Sociedade da Serra do Rodeador desta Provincia de Pernambuco" a preocupação de fixar terem partido os primeiros disparos do lado dos adeptos de Silvestre, porquanto na manhã do dia 26 se iludiram êstes com as praxes militares e tomaram os jvivas a El Rey (D. João VI) com que a tropa abria as escaramuças como sinal da esperada adesão milagrosa e saudação ao seu rei D. Sebastião. A julgar do relatório do tenente-coronel José de Sá Carneiro Pereira,é possivel que os do Rodeador tenham se defendido com alguma bravura ("disse mais que a defeza que tinham feito foi por que os Procuradores de Jesus Christo assim o tinha ordenado em nome da Santa Milagrosa" ${ }^{42}$, logo que dissipado o equívoco agindo as tropas com incrível crueldade. Em suas palavras cruas, foi incendiada a capela "que queimou tidos os feridos que estavão dentro chegando a mais de setenta inclusos algumas mulheres, e o resto foi prisioneiro, e morto, escapando-se alguns que se poderão se occultar pelas grutas da dença matta" 43 .

Diante do clamor público e das críticas à crueldade da repressão, após o inquérito foram os prisioneiros, na sua grande maioria mulheres, recambiados e postos em liberdade, enquanto as crianças órfãs foram adotadas por famílias da capital, dando-lhes o exemplo o próprio governador que resolveu proteger a três. Sabe-se dos principais que Manoel Gomes mor- 
reu na luta, Silvestre se evadiu, Estevão Fernandes, José Fernandes e Antonio Pereira foram feitos prisioneiros, enquanto Manoel da Paixão foi capturado posteriormente em Garanhuns.

Assim terminou a Cruzada ingênua dêsses sertanejos pernambucanos, mas suas idéias milenaristas e sebastianistas continuavam a ter curso até determinarem os episódios posteriores e ainda mais sangüinolentos de Pedra Bonita e Canudos ${ }^{44}$.

O episódio da Serra do Rodeador enquadra-se perfeitamente nas categorias que distinguem aos movimentos milenares: era inspirado pela idéia de salvação e pelo caráter do salvador (tomados ao catolicismo neste caso particular); constituía um movimento coletivo que beneficiaria ao grupo dos fiéis que aderissem à "sociedade" e participassem da emprêsa; propunha-se um fim terrestre com 'a libertação de Jerusalém e a conquista do "Paraíso Terreal" ali; anunciava-se iminente, com a realização das fantasias de líderes e seguidores, não tardando aparecer o rei $\mathrm{D}$. Sebastião com o seu exército mítico para ajudá-los; a transformação seria total com a submissão e conversão dos infiéis e a inauguração de uma nova era ${ }^{45}$. Além de milenar, era sebastianista êsse movimento, fazendo reviver os mitos do reaparecimento miraculoso do rei desaparecido, que desempenharia lentão o papel do Messias da tradição judaico-cristã. Isso reflete a intensidade da legenda de D. Sebastião transplantada para o Brasil e capaz, ainda por longo tempo, de continuar a capturar a imaginação popular, como o demonstrariam outros movimentos subseqüentes. Finalmente, o episcidio surgiu numa época de crise e insatisfação, congregando-se para essa cruzada tardia indivíduos de baixa condição social, 'de área relativamente isolada, possivelmente insatisfeitos com os agentes da religião oficial (a sua, dizem os depoimentos, seria "a cauza da verdadeira Fé, e Religião de Nosso Senhor Jesus Christo").

Depreende-se ainda dos documentos consultados jamais terem êles hostilizado ao clero, apenas deixando de atender às exortaçeõs dos padres que foram dissuadi-los. De outro lado, exigiam dos neófitos, a princípio, que se confessassem aos vigários e capelães. Buscavam, no entanto, êles próprios, meios mais diretos de comunicação com o sobrenatural e ação independente na conquista dos seus fins religiosos e da ventura que lhes seria então proporcionada. O líder, a exemplo de outros da sua espécie, parecia obsecado há algum tempo por suas fantasias apocalíticas e tentara mesmo anteriormente difundi-las e reunir adeptos, até que isso se the tornou possivel no Rodeador.

Da personalidade dêsse líder pouco se deduz dos documentos; apenas que, sendo pobre e analfabeto, se apresentava como porta-voz da "Santa Milagrosa" ("que este he que a Snra. lhe fallava e tinha revelação da Senhora") e pregava as revelações "que elle expunha e que todos se admiravão do que elle fazia e do que dizia" 46. Aproveitara-se da sua experiência de militar para estruturar a hierarquia do grupo e dar ao mo- 
vimento a sua caracteristica típica de verdadeira cruzada. Além disso, mantinha e impunha uma austeridade tida até como perigosa pela autoridade repressora. Não existem, porém, indicações de que o grupo fôsse submetido a excessos de autoridade, nem a práticas definidamente mórbidas ou aberrantes. Os rituais de iniciação eram relativamente simples e de ingênua feição militar-religiosa; as orações habituais, aquelas da devoção comum das gentes do interior (têrço, ofício de Nossa Senhora, etc.), completadas circunstancialmente por aquelas da inventiva dos improvisados líderes religiosos; as "penitências", familiares à gente do sertão e aqui introduzidas desde o tempo dos missionários jesuitas. Embora se lhes atribua o propósito de sair "a campo castigar os que se não quizerem alistar no seu partido", êsses cruzados não pareciam tomados de ódio aos infiéis, nem inclinados à violência. Antes, apiedavam-se dêstes e confiavam nos meios sobrenaturais para vencer tôda resistência à sua emprêsa, nem "medo algum tem de serem offendidos por que elles só he que servem a Deos e ao verdadeiro Rey" 47.

O movimento parece ter tido grande repercussão especialmente por seu vulto e pelos "milagres contados" e foi reprimido, no dizer do governador, "porque o povo se hia allucinando". Seus líderes, entretanto, parecem apenas ter vindo ao encontro do anseio de salvação e de felicidade imediata das populações que conseguiram influenciar, capitalizando sôbre o fundo comum de idéias e fantasias milenaristas (junto a crenças sebastianistas) e da frustração e ansiedade dos pobres e humildes.

\section{NOTAS}

1) Pereira da Costa, F. A. - "Folk-lore Pernambucano". Rev. Inst. Histórico e Geográfico Brasileiro, vol. 70, parte II (1907), págs. 33-35.

2) Augusto da Costa, J. - "A expedição do Rodeador". Revista Brasileira, vol. 4 (1880), págs. 341-352 (edição N. Midosi).

3) Devassa acêrca dos acontecimentos da Serra do Rodeador. Governadores de Pernambuco. Correspondência com o Ministério do Reino 1820-

21. Secção de Documentos. Arquivo Nacional (Rio); págs. 4-144, 180-187 e 264-269.

4) Ibid., pág. 24.

5) Ibid., pág. 6.

6) Ibid., pág. 25.

7) Ibid., pág. 94.

8) Ibid., pág. 24.

9) Ibid., pág. 23.

10) Ibid., pág. 89 verso. 
11) Ibid., pág. 25 .

12) Ibid., pág. 10.

13) Ibid., pág. 27.

14) Ibid., pág. 26.

15) Ibid., págs. 23 e 24.

16) Ibid., pág. 22 e verso.

17) Ibid., pág. 57 e verso.

18) Ibid., pág. 47.

19) Ibid., pág. 92.

20) Cohn, Norman - "Medieval millenarism and its bearing on the comparative study of millenarian movements". Comunicação à Conference on Religious Movements of a Millenarian Character (Chicago, 8-9 de abri] de 1960), mimeografado, pág. 4.

21) Lucio de Azevedo, J. - A Evolução do Sebastianismo. Livr. Clássica Edit., Lisboa (1947), pág. 113.

22) Ibid., pág. 114.

23) Pereira da Costa, F. A., loc. cit. e págs. 35-44; Euclydes da Cunha -- Os Sertões, 15.a ed., F. Alves, Rio, 1940; Pereira de Queiroz, M. I. La "Guerre Sainte" au Brésil: le mouvement messianique du "Contestado". F.ol. 187 (Sociologia), Fac. Fil., Univ. de S. Paulo, 1957; Schaden, Egon A Mitologia Heróica de Tribos Indígenas do Brasil, Serv. Documentação, MEC., Rio, 1959, págs. 37-59.

24) Augusto da Costa, loc. cit., pág. 50. Veja-se também Memoria Justificativa sobre a conducta do marechal de campo Luiz do Rego Barreto etc. Tip. D. Marques Leão, Lisboa (1822), págs. 15-21.

25) Ibid., pág. 47.

26) Devassa etc., pág. 87.

27) Ibid., pág. 103.

28) Ibid., pág. 23.

29) Ibid., pág. 40.

30) Ibid., pág. 27 e verso.

31) Ibid., pág. 8 e verso.

32) Ibid., pág. 22 verso.

33) Ibid., pág. 40.

34) Ibid., pág. 41.

35) Ibid., pág. 40.

36) Ibid., pág. 41 verso.

37) Ibid., pág. 96 verso.

38) Ibid., pág. 104. 
39) Ibid., pág. 23 verso.

40) Ibid., pág. 8.

41) Ibid., págs. 27 verso e 28 .

42) Ibid., pág. 24 verso.

43) Ibid., págs. 10 e 11.

44) Pereira da Costa, loc. cit., págs. 35-44; Euclydes da Cunha, loc. cit., págs. 159-214.

45) Norman Cohn, loc. cit., págs. 1 e 2 .

46) Devassa etc., pág. 89 verso.

47) Ibid., pág. 8. 